IZA DP No. 6436

The Role of Preferences and Opportunity Costs in Determining the Time Allocated to Housework

Leslie S. Stratton

March 2012 


\title{
The Role of Preferences and Opportunity Costs in Determining the Time Allocated to Housework
}

\author{
Leslie S. Stratton \\ Virginia Commonwealth University \\ and IZA
}

Discussion Paper No. 6436

March 2012

\author{
IZA \\ P.O. Box 7240 \\ 53072 Bonn \\ Germany \\ Phone: +49-228-3894-0 \\ Fax: +49-228-3894-180 \\ E-mail: iza@iza.org
}

\begin{abstract}
Any opinions expressed here are those of the author(s) and not those of IZA. Research published in this series may include views on policy, but the institute itself takes no institutional policy positions.

The Institute for the Study of Labor (IZA) in Bonn is a local and virtual international research center and a place of communication between science, politics and business. IZA is an independent nonprofit organization supported by Deutsche Post Foundation. The center is associated with the University of Bonn and offers a stimulating research environment through its international network, workshops and conferences, data service, project support, research visits and doctoral program. IZA engages in (i) original and internationally competitive research in all fields of labor economics, (ii) development of policy concepts, and (iii) dissemination of research results and concepts to the interested public.
\end{abstract}

IZA Discussion Papers often represent preliminary work and are circulated to encourage discussion. Citation of such a paper should account for its provisional character. A revised version may be available directly from the author. 


\section{ABSTRACT \\ The Role of Preferences and Opportunity Costs in Determining the Time Allocated to Housework}

The time devoted to housework in couple households is substantial. Research on intrahousehold time allocations has generally assumed that housework is a necessary evil and that the partner with the lower opportunity cost of time in the market will devote more time to home production. In reality, households/individuals are likely motivated to maximize happiness, and preferences regarding even mundane household chores differ considerably. We use information on preferences, opportunity costs, and time use from the 2000-2001 United Kingdom Time Use Survey to examine the time partners spend doing laundry, ironing, cleaning, and food shopping. While compared with other household chores such as gardening and do-it-yourself repairs, the selected activities are generally less enjoyable, preferences do vary across the population and are correlated with reported time use. Joint multivariate analysis of his and her time on weekend and weekday days as well as maid service reveals that her opportunity cost of time matters substantially more than his, but that his preferences play a greater role than hers.

JEL Classification: D13, J22

Keywords: time allocation, housework, preferences

Corresponding author:

Leslie S. Stratton

Virginia Commonwealth University

301 W. Main Street

Richmond, VA 23284-4000

USA

E-mail: Isstratt@vcu.edu 
The Role of Preferences and Opportunity Costs

in Determining the Time Allocated to Housework

The time devoted to housework is substantial. On average couple households in the United States reported spending 28 hours per week on housework in 2003, about $44 \%$ of the time these households devoted to market employment. Gender wage differences have long been attributed in part to gender differences in such household responsibilities so the consequences of these allocation decisions are substantial. Research on intrahousehold time allocation has generally assumed that housework is a necessary evil and that the partner with the least power in the household or the lowest opportunity cost of time in the market will be forced to devote more time to home production. More generally, economic theory suggests that households act to maximize happiness. While many people do find housework tasks undesirable, preferences vary and should influence time allocations. We use information on preferences, opportunity costs, and time use from the 2000-2001 United Kingdom Time Use Survey to examine the time partners spend doing laundry, ironing, cleaning, and food shopping. While compared with other household chores such as gardening and do-it-yourself repairs, the selected activities are not generally considered enjoyable, preferences do vary across the population and are correlated with reported time use. Joint multivariate analysis of his and her time on weekend and weekday days as well as maid service reveals that her opportunity cost of time matters substantially more than his, but that his preferences play a greater role than hers.

The dominant economic theory used to explain intrahousehold time allocation has been specialization and the division of labor. Becker (1991) postulates that, much as in the case of the 
two country-two good trade model, couples should optimally specialize such that one partner focuses completely on either market or home-based production. The other partner then either fully or partially specializes in production of the other good. The goal is to reap the benefits of comparative advantage and maximize the household's utility. Efficient specialization is achieved by exploiting comparative advantage.

This theory has been tested empirically by modeling time spent in home production as a function of wages or relative wages. Assuming that everyone is equally skilled at home production and all else is equal, the partner with the highest relative earnings should specialize in market production and spend less time on housework. Work by Hersch and Stratton (1994) indeed finds that the higher the husband's share of household income in American dual earner households, the less time he spends and the more time his wife spends on housework. Other researchers model household behavior using not a household utility function but a bargaining model (see Lundberg and Pollak 1996) or a collective household model (Apps and Rees 1997; Blundell, Chiappori, Meghir 2005). These approaches often also suggest a link between wages and time spent on housework. This association may arise because wages reflect household members' other opportunities or their bargaining power within the household. In either case, the prediction is similar. Higher relative/absolute wages are associated with lower housework time. There is also a substantial sociology literature documenting this relation (see for example, Evertsson and Nermo 2004). More recent work by Gupta and Ash (2008) reports a stronger link for absolute than for relative earnings in driving housework time, with a stronger relation for women. Stancanelli and Stratton (2011) also find that 'her' opportunity cost of time matters more than 'his' in determining intrahousehold time allocations to housework, but that both 
partners' opportunity costs are highly associated with the availability of time saving appliances and the decision to hire a maid.

These models of household behavior rely on a number of critical assumptions. Pollak (2011) offers a detailed critique of the Beckerian approach, but one assumption is that there are no 'process benefits' or at least no differential process benefits associated with either market or home production time. Thus, production is valued only for the goods that are produced not for the time spent in that activity. This assumption is standard as well in the labor supply literature where it is assumed that individuals work only for the money earned in the process. Housework likewise is assumed to be a necessary task that no one likes, that everyone would rather someone else performed. Yet in the sociology literature there has been substantial support for display theory also known as 'doing gender' (Brines 1994) whereby women who earn relatively high wages may contribute relatively more time to housework in order to demonstrate their feminine side. This suggests that there are social benefits associated with performing housework.

More generally, there may also be intrinsic or 'process benefits' associated with housework tasks. Kerkhofs and Kooreman (2003) and Gørtz (2011) estimate household production models that allow for the possibility of such 'process benefits' using Swedish and Danish time use data respectively. Both papers include time spent on a wide array of activities in their measure of housework - including the mundane tasks of cleaning and laundry as well as cooking, gardening, and do-it-yourself work that often constitute hobbies. Kerkhofs and Kooreman (2003) even include childcare which is well known to include a leisure component. No information on preferences is available, so process benefits are identified in these papers by relying on a household production function and a process benefit function of a particular functional form. Process benefits are effectively observed if individuals spend more time on 
housework tasks than would be predicted given their opportunity cost of time. ${ }^{1}$ That the evidence so obtained for process benefits is at best weak is perhaps not surprising given the composite amalgam of housework activities and the assumption of similar preferences by gender.

The approach taken here differs in that we use a narrower set of housework tasks for which we have data on each individual's self-reported preferences. We model not household production (for which there is no output measure) but rather the demand for inputs to household production including not only household time but also information on maid services. Clearly economic theory suggests that if an individual enjoys an activity, that individual should spend more time on that activity and be less likely to purchase a market substitute, ceteris paribus. This approach also allows us to gauge the degree of substitutability between inputs. ${ }^{2}$

\section{DATA}

The data for this analysis are drawn from the 2000-2001 United Kingdom Time Use Survey (UKTUS). To focus on intrahousehold time allocation, we restrict our sample to heterosexual couple households. Data limitations necessitate excluding those in Northern Ireland. These restrictions yield an initial sample of 3822 households. Of these, 1780 completed household, individual, and partner surveys indicating they were single couple households comprised of individuals between the ages of 20 and 59 inclusive, not enrolled in school, not in the military, not on disability, and not retired. To analyze time spent on housework, this analysis further requires complete time diaries. Each partner was asked to complete two 24 hour time

\footnotetext{
${ }^{1}$ Gørtz (2011) points out that it is not possible using this approach to distinguish between individual process benefits and household partiality for home-produced rather than market purchased goods. ${ }^{2}$ Both Gørtz (2011) and Kerkhofs and Kooreman (2003) report evidence that men and women are substitutes for one another in home production.
} 
diaries, one for a weekend day and one for a week day. Typically, each partner completed diaries for the same days. Respondents filled these diaries out in 10 minute intervals using their own words. These entries were then recoded into approximately 170 standardized activities. Our goal is to obtain reliable diary information for normal days. Restricting the analysis to households for which four diaries are completed yields a sample of 1302 observations. ${ }^{3}$ Finally, the sample is restricted to households that provide information on purchased services yielding the final estimation sample of 1291.

Of critical importance for this analysis is information on household time, purchased time, and preferences regarding common household chores. The select group of activities on which we focus are house cleaning, laundry, ironing, and food shopping. For each of these activities, the time diaries contain specific codes and the questionnaires solicit individual attitudes. Less than $5 \%$ of our sample reports spending no time on these common household activities. Households are also explicitly asked about the use of paid help for cleaning, ironing, and shopping/errands over the last four weeks. ${ }^{4}$ Only $6.7 \%$ purchase such services and $80 \%$ of these purchase cleaning services. Only a single household reports paid help for shopping/errands.

Given the small fraction of households reporting paid help and some uncertainty regarding the time purchased, we employ a dummy variable to identify paid services rather than a continuous time measure.

A possible concern with these activities is the availability of other market alternatives particularly for laundry services. No information on the use of such services was solicited by the

\footnotetext{
${ }^{3}$ Complete diaries are defined here as diaries for which at least 23 hours of data and five different activity spells are reported. The latter restriction is imposed because Juster (1985) indicates that diaries with very few distinct activities are unreliable. 'Normal' days are identified here to exclude holidays and sick days. Individuals who report spending more than 30 minutes in bed sick or twenty or more hours sick or sleeping are judged to be sick.

${ }^{4}$ We ignore reports of paid children and partners.
} 
UKTUS. However, the 2000-2001 UK Family Expenditure Survey indicates that only $2 \%$ of working age couple households used laundry services within the two weeks covered by the survey, a fraction so low that these could be vacationers. A higher percent (5.7\%) report having used dry cleaning services, but such services are often purchased not to save time but rather because of clothing choice - some clothes must be dry cleaned.

Restricting our analysis to house cleaning, laundry, ironing, and food shopping excludes many other household chores. We would have liked to include dish washing, but preference data for this activity are not available. Information on preferences regarding food preparation is available (for both everyday cooking and cooking for special occasions) as is information on time use by household members and in-house paid services, but other market alternatives for this domestic task abound in the form of pre-packaged food, delivery services, and restaurant dining. The UK Family Expenditure Survey indicates that $95 \%$ of working age couple households purchased and consumed hot or cold meals away from home during the two week period of the survey. Information on both time spent (household and paid) and preferences is also available for gardening activities and do-it-yourself home repairs. As these activities generally require home ownership, we chose to exclude them. The select set of tasks on which we focus is much more narrowly defined than that employed in earlier work on process benefits and their mundane nature would suggest that process benefits are unlikely.

Table 1 provides information on the sample means. The first four rows show the reported minutes spent on these household tasks by partner and by day of the week. The fifth row shows the fraction of households purchasing these services. Not surprisingly, women report spending more time on these activities than men (68-81 versus $11-22$ minutes) and both men and women 
report more time on weekends than on weekdays (11-13 minutes more). As mentioned above, only $6.7 \%$ of these households report hiring a maid to perform these tasks.

Preference data are the next most critical data for this analysis. The nature of these tasks is such that they are unlikely to constitute hobbies, but preferences may still vary. Preferences were reported on questionnaires each individual in the household was requested to complete. Preferences for each activity are coded on a five point scale from 'like a lot' to 'like a little', 'neither like nor dislike', 'dislike a little', and 'dislike a lot'. There are two instances in which these data are missing. First, in some cases these questionnaires were completed by proxy rather than by the individual him/herself. Proxy interviews do not contain information on preferences. About $3 \%$ of women and $13 \%$ of men are missing preference data for this reason. In some specifications, these individuals are identified with a dummy variable and coded as being indifferent regarding all the activities. ${ }^{5}$ In other specifications, these individuals are excluded from the analysis. Second, respondents could respond that they never performed the activity in lieu of identifying their preferences. Only $6 \%$ of the women reported not engaging in one of these activities. The activity women were most likely to report not performing was ironing. $4.8 \%$ of women reported they did not iron, $1.6 \%$ reported not food shopping, and less than $0.5 \%$ reported either not doing laundry or not cleaning the house. By contrast, almost $50 \%$ of men reported they did not perform one of these activities, with ironing and laundry together accounting for over $95 \%$ of these $50 \%$. Only 31 men reported not performing any of these tasks - and only 25 of these in fact reported no time in the diaries. These 25 men do not constitute the majority of men reporting no time on these activities: fully 644 men report no weekday or weekend time on these activities on the diary days for which they report. As most of these tasks

\footnotetext{
${ }^{5}$ A handful of men reported not knowing their preferences regarding an activity. Preferences in these five instances were also assumed to reflect indifference.
} 
while routinely performed are not performed daily, many of these zero values reflect the narrow window of the time diary data. While it seems likely that individuals who report no time on an activity probably do not enjoy that activity, as an individual who likes an activities will find the time for it, we chose to be conservative in our aggregate measure of preferences and assume that those who say they do not perform an activity neither like nor dislike that activity. We conduct sensitivity analysis in order to gauge the impact this assumption has on our estimates.

Preference data will be of little value if, as much of the literature to date assumes, every individual reports disliking all of these activities. Figure 1 displays the preference data by gender and activity for those reporting preferences. The lighter the color, the more the enjoyment derived from the activity. Men are less likely to report enjoying any of these activities than women, but there is substantial variation by activity. Men and women alike are less likely to report enjoying ironing, but somewhat more likely to report enjoying food shopping. Women appear to enjoy doing laundry substantially more than men. A simple average of the preference values is constructed to measure overall preferences. A value of 1 indicates the respondent enjoys all the activities a lot. A value of -1 indicates the respondent dislikes all the activities a lot. The sample average of these values is very close to zero (see Table 1). Figure 2 illustrates the distribution of these average preferences by gender. These illustrations suggest there is sufficient heterogeneity in terms of preferences to warrant controlling for them in the analysis of time use.

The next most important explanatory variables are the measures of opportunity cost. In the case of maid services, we use regional and time differences in the natural log of the median gross hourly pay for elementary occupations in sales and services within the UK as reported in the British Annual Survey of Hours and Earnings conducted by the Office of National Statistics. 
The British Quarterly Labour Force Survey indicates that over half of those in this occupational category are "cleaners, domestics" or maids. ${ }^{6}$ As the primary expense associated with maid service is the labor cost, this measure will at least roughly capture the market price of such services.

The opportunity cost of each partner's time is captured using his/her predicted natural log of net hourly earnings. These predictions are generated by estimating standard Heckman selection corrected wage models separately by gender on the full sample of 20-59 year olds who are not in school, provide personal (and partner) information on education and potential experience as well as household data on non-labor income receipt. The middle $98 \%$ of wages for non-self-employed workers are modeled as a function of detailed education measures, a quadratic in potential experience, region of residence, marital status, the local unemployment rate, rural/urban residence, and a dummy to identify minorities. The estimation samples consist of 2571 men of whom 1351 report viable wages and 3015 women of whom 1618 report viable wages. The majority of the men missing wage information are either self-employed or are employed but fail to report earnings. The majority of the women missing wage information were not employed. The selection equations include all the variables included in the log wage model as well as information on household composition, partner characteristics, non-labor income receipt, health indicators, seasonal dummies, and a dummy to indicate access to a computer. Net earnings are the appropriate measure of opportunity cost as they more closely than gross earnings reflect disposable income. Sample means reported in Table 1 indicate, as expected, that on average men's opportunity cost of time is higher than women's.

As our focus is upon estimating a system of demand equations for the inputs to household production, it is necessary to control for non-labor income, household-specific factors

\footnotetext{
${ }^{6}$ Results using the pay of "domestic staff and related occupations" were substantially similar.
} 
influencing the need for such services, and individual-specific factors likely related to productivity in home production. To this end we include a dummy variable identifying those households who receive income from rent, interest, or alimony; a dummy variable identifying those who reside in London where cultural attitudes towards employment and maid services may differ; information on household composition (the number of other adults in the household, the number of children of various ages); a dummy to identify diaries completed during the summer that may incorporate seasonal differences in household time constraints and needs; as well as controls for each partner's age and gross educational background. Sample statistics for these control variables are also reported in Table 1.

\section{EMPIRICAL SPECIFICATION}

We model the time inputs to home production using a system of linear equations (see Aguiar and Hurst 2005, Hamermesh 2007, and Stancanelli and Stratton 2011). While capital inputs are likely important as well, the capital goods most closely associated with these activities (clothes washers, vacuums, and irons) are likely owned by most households. Indeed, the UKTUS indicates that fully $98 \%$ of the households in our sample have the most costly of these, a clothes washer. With little variation in access to capital equipment, we proceed with estimation of the time inputs alone.

Each partner's time input is modeled separately for weekend and weekday days as follows:

Time $_{\mathrm{hjk}}=\beta_{0 \mathrm{jk}}+\alpha_{\mathrm{mjk}} \ln \mathrm{W}_{\mathrm{hm}}+\alpha_{\mathrm{fjk}} \ln \mathrm{W}_{\mathrm{hf}}+\gamma_{\mathrm{jk}} \ln \mathrm{P}_{\mathrm{hs}}+\delta_{\mathrm{mjk}} \operatorname{Pr}_{\mathrm{hm}}+\delta_{\mathrm{fjk}} \operatorname{Pr}_{\mathrm{hf}}+\zeta_{\mathrm{jk}} \mathrm{X}_{\mathrm{hj}}+\varepsilon_{\mathrm{hjk}}$

where $\mathrm{h}$ represents the household, $\mathrm{j}$ the partner ( $\mathrm{m}$ for male and $\mathrm{f}$ for female), and $\mathrm{k}$ represents the day of the week (weekend, week day). W stands for the opportunity cost of time and P the 
cost of maid service. Pr stands for preferences, $\mathrm{X}$ is a vector of other covariates, and $\varepsilon$ is the random error.

The decision to purchase maid services or market alternatives to household time inputs is modeled in a fifth equation.

Maid $_{\mathrm{h}}=\beta_{1}+\alpha_{\mathrm{ms}} \ln \mathrm{W}_{\mathrm{hm}}+\alpha_{\mathrm{fs}} \ln \mathrm{W}_{\mathrm{hf}}+\tau \ln \mathrm{P}_{\mathrm{hs}}+\eta_{\mathrm{ms}} \operatorname{Pr}_{\mathrm{hm}}+\eta_{\mathrm{fs}} \operatorname{Pr}_{\mathrm{hf}}+\lambda X_{\mathrm{hj}}+\mu_{\mathrm{h}}$

While Maid is a continuous variable reflecting hours purchased, we model only the decision to use maid services, not the hours purchased. Thus, we estimate a probit model using the dependent variable,

$$
\begin{aligned}
& \operatorname{Maid}_{\mathrm{h}} *=1 \text { if } \text { Maid }_{\mathrm{h}}>0 \\
& \text { Maid }_{\mathrm{h}} *=0 \text { otherwise. }
\end{aligned}
$$

This five equation model is estimated jointly by simulated maximum likelihood using the Geweke, Hajivassiliou, and Keane (GHK) algorithm. See Roodman (2007 and 2009) for a further discussion. The advantage of this estimation technique is that it allows us to estimate the degree of correlation between the observables across all five equations, increasing efficiency and shedding further light on the interrelations between these resources. As opportunity cost is imputed, it will introduce additional variability into the estimates. We address this by bootstrapping our estimates. A robust estimation approach is employed to account for heteroskedasticity.

\section{RESULTS}

The estimated coefficients for the opportunity cost and preference measures from this system of equations are presented in Table 2. In the case of the probit model, both coefficient estimates and analytic marginal effects are reported. These marginal effects are calculated for a 
household with sample mean opportunity costs and one child age 10-16, else modal characteristics which in this case are zero values for all other parameters. The linear in the log specification means the coefficients to the opportunity cost measures in the time use equations are marginal effects. All marginal effects are for the case of a doubling of value. Parameter estimates for the remaining covariates are reported in Appendix A. Table 3 presents estimates of the cross-equation correlations of the residuals.

These results indicate that the opportunity cost measures are statistically and economically significant factors driving the decision to hire a maid. A $10 \%$ increase in his opportunity cost increases the household's probability of having maid service by almost $0.8 \%$. A $10 \%$ increase in her opportunity cost increases the household's probability of having maid service by about $1 \%$. Given that the baseline probability of having maid service is only $3.5 \%$, these are substantial marginal effects. Not surprisingly, households living in areas where maid prices are higher are less likely to have maid service with a $10 \%$ increase in the cost of maid service associated with a $2.5 \%$ decrease in the probability of having maid service. Individual preferences regarding these activities have little bearing on whether or not maid services are used.

The time household members report spending on housework is also sensitive to opportunity costs - particularly her's and the maid's. His opportunity cost is in no case individually statistically significant, nor is it jointly significant (p-value 0.80). By contrast, in households where women have higher opportunity costs, the time men spend on these activities increases on weekends while the time women spend on weekdays decreases. These associations are statistically and economically significant. A $10 \%$ increase in her opportunity costs is associated on average with a 2.3 minute per day increase in his weekend time and a 2.4 minute 
per day decrease is her weekday time. These represent a $10 \%$ increase in his average time and a $4 \%$ decrease in her average time on these days. Weekend time by both partners also has a significant and substantial association with maid prices. A $10 \%$ increase in the cost of maid service increases his weekend day time by 9.6 minutes or $43 \%$ while it increases her time by about 14.2 minutes or about $17 \%$. This association between weekend and maid time is similar to that reported in Stancanelli and Stratton (2011), who suggest that services provided by maids are closer substitutes for weekend than for weekday time.

While 'her' opportunity cost but not 'his' is an important factor driving household time allocations to these tasks, however, it is 'his' not 'her' preferences that matter. Her preferences are neither individually nor jointly significant (p-value 0.49 ), his are (with a joint p-value of 0.001). A change in his preferences from indifference to liking a lot (or from dislikes a lot to indifference) increases the time he reports spending on housework by about 7 minutes per day (corresponding to a $59 \%$ increase in average time on weekdays, $31 \%$ on weekends) and decreases the time she reports spending on housework by 6-10 minutes per day (corresponding to a $14 \%$ decrease in weekdays and a $7 \%$ decrease on weekends). Likewise (results reported in the Appendix), the associations between women for whom proxy interviews are conducted and household time use are in every equation insignificant (with a joint $p$-value of 0.37 ) while men for whom proxy interviews are conducted report spending significantly less time on these activities on weekdays while their partners report significantly more time on weekdays. There is no significant association between completing proxy interviews and weekend time allocations. We believe those men who do not fill out their own questionnaires were likely 'too busy' to do so and this is reflected in household time allocations to these tasks. However, men on average are also less likely to report enjoying these activities and preferences for those with proxy 
interviews are assumed in the construction of the preference indicator to reflect indifference not dislike. Thus, the coefficient to the proxy measure for men may also be negative because these men on average liked these activities less. The effect of men's preferences on household time allocations is notable particularly in the case of his weekday time, where his preferences and the dummy variable identifying men with proxy interviews are the only variables having statistically significant coefficient values.

Relatively few other parameters are statistically significant. Having some source of nonlabor income is positively and significantly associated with having maid service, while being a cohabiting rather than a married couple is significantly negatively associated with having maid service. As stated above, no other variables are significantly associated with his weekday housework time, while having a residence in London significantly reduces his weekend day time. Children significantly increase her housework time. Each child under the age of 5 is associated with a 19.5 minute increase in her weekday time. Children between the ages of 4 and 10 increase her weekday time by 15.5 minutes and her weekend day time by 9.5 minutes. Children age 10 and above are associated with 8 more minutes of housework time on weekdays and almost 19 more minutes on weekend days. Older women spend more time on housework on weekdays, while cohabiting women spend less. More educated women spend less time on housework on weekend days.

Table 3 presents estimates of the cross-equation correlation terms. These indicate that the residuals from the probit equation on maid service are not significantly correlated with those from any time use equation, though they are marginally negatively associated with her weekday time. His (her) weekday and weekend time are positively and significantly correlated in the residuals, suggesting either common preferences for housework or productivity effects. His and 
her weekday times are negatively correlated in the residuals, possibly suggesting that men and women are substitutes for one another on weekdays and when one partner does more that frees the other partner. His and her weekend day times are positively correlated in the residuals, suggesting that partners may be complementary inputs on the weekends, perhaps because of shared time on tasks, perhaps because they work together. Finally his and her time on different days are negatively correlated in the residuals, significantly so in the case of his weekend and her weekday time. This relation suggests that if he spends more time for unobserved reasons on housework on weekends, she may have less to do on weekdays.

These estimates assume the effect of preferences on housework time is symmetric, that the impact of a change from dislike a lot to indifference is the same as the impact of a change from indifference to like a lot. We test this by estimating a specification in which we distinguish separately between likes and dislikes, particularly for men. These results indicate that men's time use is influenced more by their dislike of housework whereas women's time use is impacted primarily by men who enjoy housework.

We also check the robustness of our estimates by running analyses with different measures of opportunity costs, different measures of preferences, and different samples. The market price of maid services we use in the results reported above comes from an industry survey, varies only by region and year, and includes a number of occupations other than domestic services. As such it is perhaps surprising that the results with respect to this cost measure are so robust. The maid price has a negative association with having a maid that is marginally significant and a positive association with household time on weekend days that is consistent across a broad array of specifications. We attempted to construct an alternate cost measure using wage data from the British Quarterly Labour Force Survey (LFS) for 'cleaners, 
domestics', however even when aggregated at the regional level, the number of such workers was so small we chose not to pursue this analysis. The mean value of the median wage so calculated is uniformly lower than that provided in the industry survey - not surprisingly given that the LFS likely includes many more individuals who are self-employed. However, the correlation between the LFS and the industry values is 0.90 lending further credibility to the industry measures we do use.

Alternate measures of the opportunity cost of time of the partners were constructed with more success. One was an imputed wage relying entirely on education, potential experience (current age minus age began work after school), and regional variation. This measure yielded results comparable to those reported here, albeit her value of time is somewhat less significantly associated with her time use. Matched wages using either the full set of variables employed in the wage imputation or only potential experience and detailed education yield if anything stronger results. Her preferences regarding these household tasks become significantly negatively related to the use of maid services. If she likes these activities, the household is less likely to hire a maid. Her opportunity cost is no longer significantly related to his time when matched with the full set of covariates but is significantly positively correlated with his time on both weekends and weekdays when using the more limited set of covariates. Her weekday housework time becomes positively and significantly related to her preferences and in the case of the simple matching function positively and significantly related to his opportunity costs.

Although opportunity cost measures are by no means straightforward, preferences are by their very nature more difficult to capture. The main measure used here gives each activity equal weight and assumes indifference when no response is provided. An alternative measure that averages preferences only over those activities for which preferences are reported yields results 
that are similar in sign and significance. Another measure that weights the preferences based on sample average (not gender specific) time reported on the activity yields results that are even stronger. Men's preferences are now in all cases positively and significantly related to their time and negatively and significantly related to her time. Women's preferences are now negatively and significantly related to the use of maid services. Wage effects are substantially the same.

Dropping households for which there were proxy interviews yielded a substantially smaller sample (1081 households) and reduces the statistical significance of some of the wage effects - particularly the impact of his wage in the maid service equation and the impact of her wage on her weekday time. Overall, her wage but not his remains a significant determinant of household time. The role of preferences is robust to this sample change. His preference measures have the same size and significance as those reported in the full sample, while her preferences remain unrelated to reported time. The results are similar when individuals who report no preference data are dropped. Restricting the sample to dual earner households has similar results with her wages becoming less statistically significant and his preferences remaining statistically significant. The price of maids remains a significant determinant of their weekend time and her preferences become significantly negatively related to use of maid services. The sensitivity analysis reveals a robust relation between his preferences and reported household time use.

\section{CONCLUSION}

Analyses of the time allocated to housework in couple households have to date assumed that housework is an undesirable task that no one wants to perform or found little evidence of process benefits. We further probe this assumption, looking at a set of simple household tasks - 
cleaning, laundry, ironing, and food shopping - that require little skill and for which we have information on individual preferences. Comparative advantage for these tasks is likely driven by relative wages, but relative preferences may also be important. In order to control for market provision of these services, we also model the decision to hire a maid.

Using data from Great Britain, we find some support for Becker's model of intrahousehold specialization. The opportunity cost of maid services is negatively related to the decision to use maid services and positively and significantly related to the time each partner spends on weekends on these basic household tasks. The opportunity costs of time for both partners are likewise significantly positively associated with the decision to use maid services. These results indicate that maid service is indeed a substitute for household labor, particularly on weekend days. As is the case with men's labor supply, his opportunity cost of time is not significantly associated with the time he allocates to housework. Her opportunity cost of time is, however, positively and significantly associated with his weekend housework time and negatively and significantly associated with her weekday housework time. Thus, opportunity costs are important in determining time allocation and specialization, with her opportunity cost of time mattering more than his.

However, we also find significant evidence of process benefits. While women's preferences do not seem to play a substantial role, except perhaps in the decision to hire a maid, men's preferences do. The more men report disliking housework, the less time they report spending on housework and the more time their partners' report spending on housework, particularly on weekdays. Sensitivity tests reveal that this effect operates primarily through men who dislike housework, not men who like housework. These findings indicate that utility maximizing behavior is observed even for such mundane tasks as cleaning and laundry and may 
account for much of the heterogeneity observed in previous studies of time allocation. That these preferences differ substantially across the population even by gender and on average reflect indifference may explain why previous attempts to measure gender-specific process benefits have been unsuccessful. Finally, if gender wage differences are attributable to gender differences in household responsibilities it is rather disturbing that it is his preferences not hers that matter.

Overall these results highlight the importance of addressing not just opportunity costs but also preferences when modeling time allocation decisions. That preferences should be this important when looking at such everyday chores as cleaning and laundry is surprising and suggests that preferences likely play an even greater role in decisions pertaining to other time uses - even employment. Decisions regarding job choice and retirement, for example, may be highly dependent on how much pleasure individuals expect to derive from their jobs. To this end, this analysis provides significant support for the growing movement to integrate well-being into economic research. 
Bibliography

Aguiar, Mark and Erik Hurst. (2005). "Consumption versus Expenditure." Journal of Political Economy, Vol. 113, No 5, pp. 919-948.

Apps, Patricia F. and Ray Rees. (1997). “Collective Labour Supply and Household Production.” Journal of Political Economy, Vol. 105, No. 1, pp. 178-190.

Becker, Gary S. (1991). A Treatise on the Family. Cambridge, MA: Harvard University Press. Blundell, Richard, Pierre-André Chiappori, and Costas Meghir. (2005). "Collective Labor Supply with Children.” Journal of Political Economy, Vol. 113, No. 6, pp. 1277-1306. Brines, Julie. (1994). "Economic Dependency, Gender, and the Division of Labor at Home." American Journal of Sociology, Vol. 100, No. 3, pp. 652-688.

Evertsson, Marie and Magnus Nermo. (2004). "Dependence within Families and the Division of Labor: Comparing Sweden and the United States." Journal of Marriage and Family, Vol. 66 (December), pp. 1272-1286.

Gørtz, Mette. (2011). "Home production - Enjoying the process or the product?" International Journal of Time Use Research, Vol. 8, No. 1, pp. 85-109.

Gupta, Sanjiv and Michael Ash. (2008). "Whose Money, Whose Time? A Nonparametric Approach to Modeling Time Spent on Housework in the United States.” Feminist Economics, Vol. 14, No. 1, pp. 93-120.

Hamermesh, Daniel. (2007). "Time to Eat: Household Production under Increasing Income Inequality." American Journal of Agricultural Economics, Vol. 89, No. 4, pp. 852-863.

Hersch, Joni and Leslie S. Stratton. (1994). "Housework, Wages, and the Division of Housework Time for Employed Spouses". The American Economic Review, Vol. 84, No. 2 (May), pp. 120-125. 
Ipsos-RSL and Office for National Statistics. (2003). United Kingdom Time Use Survey, 2000 [computer file]. 3rd Edition. Colchester, Essex: UK Data Archive [distributor], September. SN: 4504.

Juster, F. Thomas. (1985). “The Validity and Quality of Time Use Estimates Obtained from Recall Diaries.” In: F. Thomas Juster and Frank P. Stafford (eds.) Time, Goods, and Well-Being. Survey Research Center, Institute for Social Research, University of Michigan, Ann Arbor, Michigan, pp. 63-91.

Kerkhofs, Marcel and Peter Kooreman. (2003). "Identification and Estimation of a Class of Household Production Models." Journal of Applied Econometrics, Vol. 18, No. 3, pp. $337-369$.

Lundberg, Shelley and Robert A. Pollak. (1996). "Bargaining and Distribution in Marriage." Journal of Economic Perspectives, Vol. 10, No. 4 (Autumn), pp. 139-158.

Pollak, Robert A. (2011). “Allocating Time: Individuals’ Technologies, Household Technology, Perfect Substitutes, and Specialization.” NBER Working Paper \#17529. October.

Roodman, David. (2009). "Estimating Fully Observed Recursive Mixed-Process Models with cmp.” Working Papers 168, Center for Global Development.

Roodman, David. (2007). "CMP: Stata module to implement conditional (recursive) mixed process estimator.” Statistical Software Components S456882, Boston College Department of Economics, revised 22 May 2009.

Stancanelli, Elena G. F. and Leslie S. Stratton. (2011). "Maids, appliances, and household work: The demand for inputs to domestic production." November. 
Figure 1

Preferences by Gender and Activity
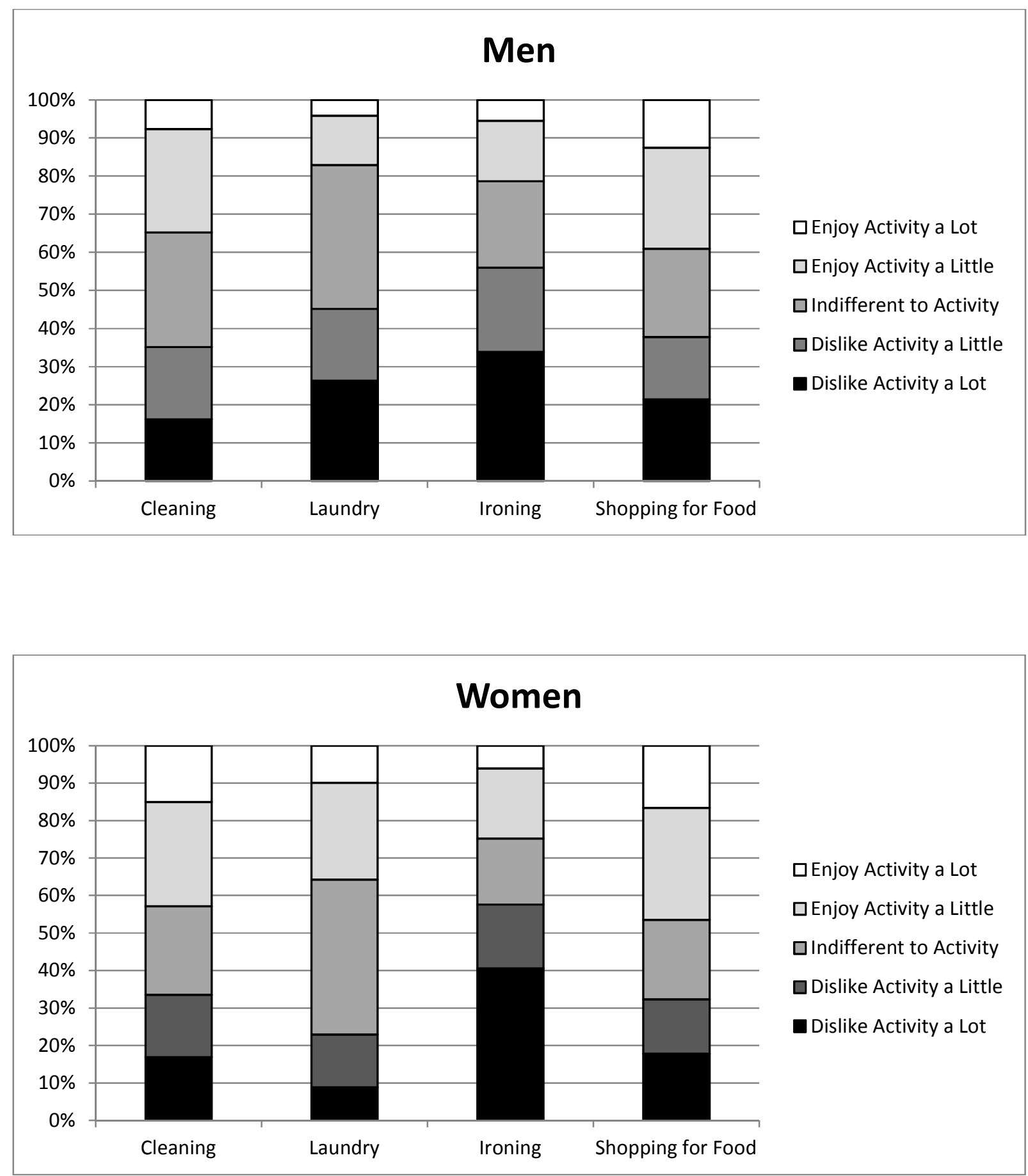
Figure 2

Average Preferences by Gender
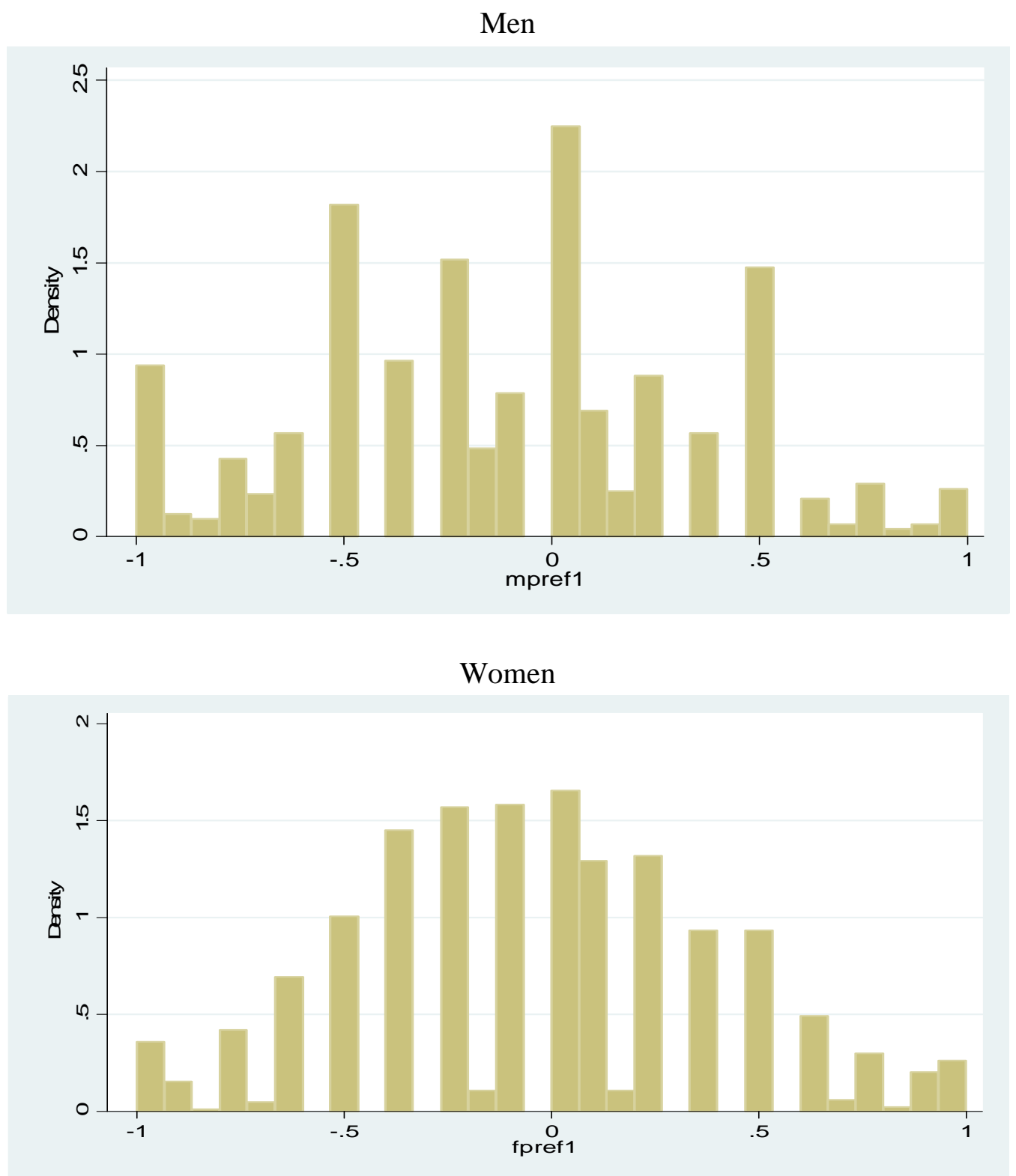

Excludes those for whom proxy interviews were provided as well as individuals who report they do not perform any of the four activities on which this analysis is focused. These restrictions substantially decrease the frequency of zero values. 


\section{Table 1 \\ Sample Statistics}

Couples in UKTUS

Dependent Variables:

Man's Weekday Time (minutes)

$\underline{\text { Mean }}$ Std. Dev.

Man's Weekend Time (minutes)

11.43

29.31

Woman's Weekday Time (minutes)

22.36

43.57

Woman's Weekend Time (minutes)

68.37

72.12

Have Maid Service (\%)

81.49

80.25

6.74

25.08

Preference Data:

Woman's survey by proxy

$0.03 \quad 0.17$

Man's survey by proxy

$0.13 \quad 0.34$

Woman's Preferences

$-0.04$

0.43

Man's Preferences

$-0.10$

0.43

Other Covariates:

Ln Median Price of Maid

Man's Ln Opportunity Cost

Woman's Ln Opportunity Cost

0.25

Receive Non-Labor Income

Residence in London

0.25

Cohabiting

0.38

Number of Other Adults

0.18

0.60

Number of Children age 0-2

0.28

0.37

Number of Children age 3-4

0.17

0.32

Number of Children age 5-9

0.12

0.43

Number of Children age 10-16

Summer

0.32

0.43

Woman's Age

Woman has University Education

Man has University Education

Number of Households 
Table 2

Opportunity Cost and Preference Effects

\begin{tabular}{|c|c|c|c|c|c|c|c|c|}
\hline & $\begin{array}{c}\text { Has Maic } \\
\text { Service }\end{array}$ & & $\begin{array}{c}\text { His Weekday } \\
\text { Time }\end{array}$ & $\begin{array}{c}\text { His Weeke } \\
\text { Time }\end{array}$ & & $\begin{array}{c}\text { Her Weekda } \\
\text { Time }\end{array}$ & & $\begin{array}{l}\text { Her Weekenc } \\
\text { Time }\end{array}$ \\
\hline & $\underline{\text { Coefficient }}$ & & $\underline{\text { Coefficient }}$ & $\underline{\text { Coefficient }}$ & & $\underline{\text { Coefficient }}$ & & $\underline{\text { Coefficient }}$ \\
\hline Ln(His Opportunity Cost) & $\begin{array}{r}1.0249 \\
(0.4387) \\
{[0.0791]}\end{array}$ & $* *$ & $\begin{array}{r}3.7447 \\
(5.1477)\end{array}$ & $\begin{array}{r}0.3160 \\
(8.0103)\end{array}$ & & $\begin{array}{r}-0.9540 \\
(11.6971)\end{array}$ & & $\begin{array}{c}-18.3579 \\
(15.8889)\end{array}$ \\
\hline Ln(Her Opportunity Cost) & $\begin{array}{r}1.3049 \\
(0.3745) \\
{[0.1007]}\end{array}$ & $* * *$ & $\begin{array}{r}2.0663 \\
(5.4731)\end{array}$ & $\begin{array}{l}23.4561 \\
(6.3171)\end{array}$ & $* * *$ & $\begin{array}{r}-24.0687 \\
(13.3883)\end{array}$ & $*$ & $\begin{array}{r}19.9105 \\
(15.8830)\end{array}$ \\
\hline Ln(Median Maid's Wage) & $\begin{array}{r}-3.2292 \\
(2.1156) \\
{[-0.2493]}\end{array}$ & & $\begin{array}{r}27.7889 \\
(29.5231)\end{array}$ & $\begin{array}{r}95.5840 \\
(44.6308)\end{array}$ & $* *$ & $\begin{array}{r}-30.3433 \\
(66.8881)\end{array}$ & & $\begin{array}{r}142.4515 \\
(74.3855)\end{array}$ \\
\hline Her Preferences & $\begin{array}{r}-0.2037 \\
(0.1731) \\
{[-0.0157]}\end{array}$ & & $\begin{array}{r}2.7705 \\
(1.9560)\end{array}$ & $\begin{array}{r}0.4327 \\
(3.0100)\end{array}$ & & $\begin{array}{r}4.1231 \\
(5.0744)\end{array}$ & & $\begin{array}{r}2.3127 \\
(6.0121)\end{array}$ \\
\hline His Preferences & $\begin{array}{r}0.1807 \\
(0.1473) \\
{[0.0139]}\end{array}$ & & $\begin{array}{r}6.7889 \quad * * * \\
(1.9466)\end{array}$ & $\begin{array}{r}7.0982 \\
(2.8709)\end{array}$ & $* *$ & $\begin{array}{r}-9.7105 \\
(5.5701)\end{array}$ & $*$ & $\begin{array}{r}-6.0025 \\
(5.2283)\end{array}$ \\
\hline
\end{tabular}

Standard errors are reported in parentheses below parameter estimates.

Asterisks indicate 2-sided significance level: *** 1\%,**5\%,*10\%.

All equations include controls for marital status, residence in London, the number of other adults, the number of children age 0-2, the number of

children age 3-5, the number of children age 6-9, the number of children age 10-16, a dummy for non-labor income, a dummy for summer interviews, as well as controls for his and her age, university education, and proxy interview status and an intercept. 
Table 3

\section{Cross-Equation Correlations}

$\begin{array}{cccc}\text { Has Maid } & \text { His Weekday } & \text { His Weekend } & \text { Her Weekday } \\ \text { Service } & \text { Time } & \text { Time } & \text { Time }\end{array}$

Correlation with

His Weekday Time $\quad-0.0871$

$(0.0841)$

His Weekend Time $\quad 0.0555$

$(0.0524)$

Her Weekday Time $\quad-0.0853$

(0.0656)

Her Weekend Time

$-0.0127$

(0.0636)

$\begin{array}{rlrr}0.1397 & * * * & & \\ (0.0327) & & & \\ -0.0657 & * * * & -0.0559 & * * \\ (0.0253) & & (0.0244) & \\ -0.0365 & & 0.0712 & * \\ (0.0296) & & (0.0394) & \end{array}$

0.0677

(0.0317)

Standard errors are reported in parentheses below parameter estimates.

Asterisks indicate 2-sided significance level: *** 1\%,**5\%,*10\%.

All equations include the variables listed in Table 2 as well as controls for marital status, residence in London, the

number of other adults, the number of children age $0-2$, the number of children age 3-5, the number of children age 6-

9 , the number of children age 10-16, a dummy for non-labor income, a dummy for summer interviews, as well as

controls for his and her age, university education, and proxy interview status and an intercept. 


\section{Appendix Table A1}

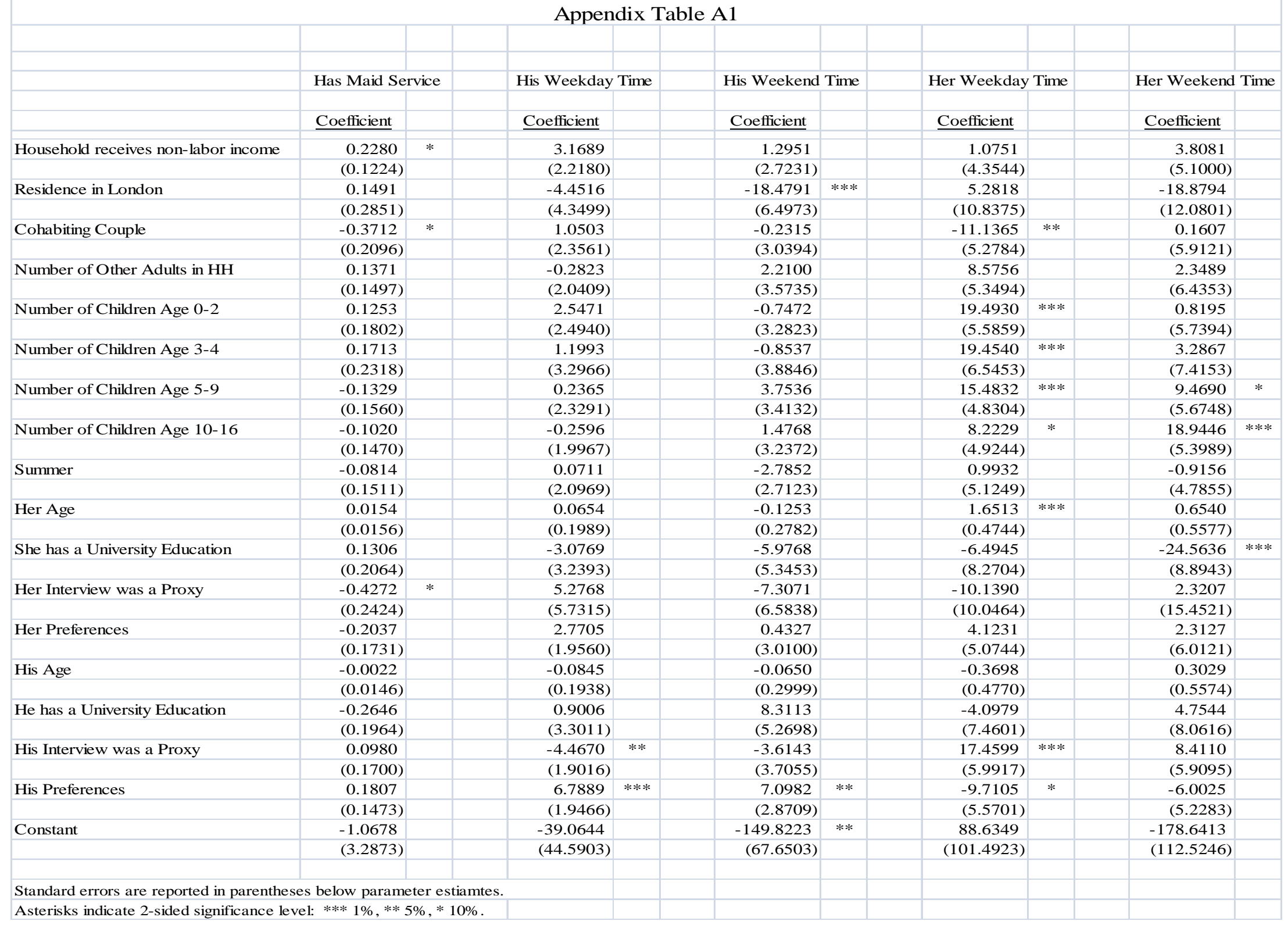

